American Journal of Pharmaceutical Education 2020; 84 (7) Article 7925.

\title{
COMMENTARY
}

\section{Faculty Burnout in Pharmacy Education}

\author{
Patricia Darbishire, PharmD, ${ }^{\mathrm{a}, \mathrm{b}}$ Alex N. Isaacs, PharmD, ${ }^{\mathrm{a}}$ Monica L. Miller, PharmD, MS ${ }^{\mathrm{a}}$ \\ ${ }^{a}$ Purdue University College of Pharmacy, West Lafayette, Indiana \\ ${ }^{\mathrm{b}}$ Editorial Board Member, American Journal of Pharmaceutical Education, Arlington, Virginia \\ Submitted November 11, 2019; accepted December 4, 2019; published July 2020.
}

\begin{abstract}
Burnout negatively affects health care faculty members, their professions, and patient care. Academic institutions are culpable in regard to establishing reasonable expectations and a supportive work culture. Together, the health professions must proactively evaluate, develop, and implement strategies to minimize faculty burnout. This commentary suggests multiple ways to address faculty burnout.
\end{abstract}

Keywords: burnout, pharmacy faculty, stress

\section{INTRODUCTION}

Student wellness is at the forefront of our Academy's priorities. ${ }^{1}$ According to the Center for Collegiate Mental Health, student disclosures of mental health issues such as anxiety, depression, and thoughts of self-harm have increased dramatically, and the number of students seeking counseling and wellness services for these issues is also on the rise. ${ }^{2}$ Pharmacy online networking and collaboration platforms, such as the American Association of Colleges of Pharmacy (AACP) Connect, are inundated with dialogue about stress management and mindfulness skills for students. ${ }^{3}$ To meet the need, universities are developing and endorsing online self-help resources, such as wellness phone applications, to complement overloaded student counseling services. ${ }^{4}$

In addition to concern for students, there is growing apprehension within professional circles regarding the well-being of pharmacists and other licensed health care professionals. To address the concerns, the American Pharmacists Association, along with the American Association of Colleges of Pharmacy (AACP), Accreditation Council for Pharmacy Education, National Association of Boards of Pharmacy and National Alliance of State Pharmacy Associations planned and conducted the Enhancing Well-Being and Resilience Among the Pharmacist Workforce: A National Consensus Conference, in July 2019, which resulted in 50 recommendations on how to enhance well-being. ${ }^{5}$ Likewise, the National Academy of Medicine created the Action Collaborative on Clinician Well-Being and Resilience to address similar issues within practice. In October 2019, the National Academy

Corresponding Author: Patricia Darbishire, Purdue

University College of Pharmacy, 575 Stadium Mall Dr., West Lafayette, IN 47907. Tel: 765-494-1380. Email:

darbishi@purdue.edu of Medicine released a report entitled Taking Action Against Burnout: A Systems Approach to Professional Well-Being. ${ }^{6}$ The importance of faculty well-being is recognized within our Academy. ${ }^{1,3,7}$ Research articles on well-being have been prevalent within the academic literature since the late 1970s; however, there is renewed discussion within the last decade..$^{7-9}$

Professional burnout has been described as a syndrome comprised of three dimensions: emotional exhaustion, depersonalization, and a feeling of low personal accomplishment at work. ${ }^{10}$ Literature suggests burnout is particularly significant among faculty members in pharmacy, medicine, and nursing because of the need for these professionals to balance multiple, high-level responsibilities, including teaching, research, engagement, and committee work, as well as patient care for many. 7,8

As expected, types of stressors and the rate of burnout differ among faculty groups. ${ }^{8,9}$ For instance, non-tenured clinical-track faculty members generally experience the highest rates of burnout, indicating an area of increasing concern as numbers of non-tenure clinical-track faculty members have steadily increased to over $50 \%$ of the current academic pharmacy workforce. ${ }^{9-11}$

The purpose of this commentary is a call to action on a significant issue affecting the personal and professional well-being of pharmacy faculty members. This article describes evidence-based predictors and consequences, as well as highlights best practices and potential solutions in an attempt to positively impact wellbeing, academic faculty recruitment and retention, and patient safety.

\section{Predictors}

The literature reveals a variety of predictors of stress and burnout for health professions faculty members. These include heavy workload, fatigue, poor work-life balance, female gender, having young children, multiple 


\section{American Journal of Pharmaceutical Education 2020; 84 (7) Article 7925.}

conflicting work responsibilities, negative work culture, policies, and inequities, as well as lower faculty rank and limited autonomy, collegiality, community, resources, training, rewards, and/or prestige. ${ }^{7,8,12}$ El-Ibiary and colleagues measured the level of burnout and its predictors among 758 US pharmacy practice faculty members. ${ }^{7}$ Emotional exhaustion was identified in $41 \%$ of participants and was higher in women, assistant professors, and those without an outlet, such as a hobby. Having young children or no mentor led to increased depersonalization. The authors concluded that large numbers of US pharmacy practice faculty members are suffering from burnout. $^{7}$ Strong predictors that have been noted among physician faculty members included heavy patient care responsibilities, lack of personal time, and poor work-life balance. ${ }^{12}$ Common predictors in clinical nursing faculty members included younger age, emotional exhaustion, and depersonalization. ${ }^{9}$

\section{Consequences}

There are significant consequences to burnout, including higher rates of depression, self-medication with illicit drugs, alcohol abuse, suicidality, diminished patient satisfaction scores, and high employee turnover rates. ${ }^{8,13}$ Burnout has substantial personal impact and negatively affects academic institutions and our academy as a whole, particularly in the areas of faculty recruitment and retention. While there is a lack of data within pharmacy education, a survey on careers in academic medicine noted that $17 \%$ of medical residents described burnout as a reason not to pursue an academic position. ${ }^{14}$ Another study found that over $40 \%$ of medical faculty members intend to leave academia because of burnout. ${ }^{15}$ High burnout rates are also a predictive factor for nursing faculty members to leave academic positions. ${ }^{8}$

Burnout is a clear deterrent to AACP's strategic plan, which includes the priorities of enriching the applicant pipeline and creating a new portrait of pharmacy and pharmacy careers. ${ }^{16}$ We also know that burnout negatively affects the quality of patient care delivered by pharmacists, as evidenced by increased errors and decreased patient satisfaction of care. ${ }^{13}$ There is little known about the impact of faculty burnout on students, but it likely affects the quality of education delivered. This is an important area for exploration. ${ }^{17}$

\section{Solutions}

The AACP is committed to health care provider, educator, and student well-being and resilience. AACP is a collaborating partner with the National Academy of Medicine, which also recognizes the importance of this issue. ${ }^{1}$ Unfortunately, evidence suggests that individual institutions of higher learning have not embraced the call for faculty wellness to the same extent as they have for student wellness. ${ }^{13}$ Because predictors are the foundation for preventative and rehabilitation strategies, collaborative efforts across health care professions and universities in analyzing predictors would facilitate solutions and policies aimed at reducing faculty burnout. ${ }^{14,18}$

We are calling for those in supervisory positions to include predictive risk factors based on faculty groups/ roles as a component of every pharmacy faculty member's annual performance review. Risks should be discussed and an evaluation of the faculty members' wellbeing should be conducted. Together, supervisors and employees should develop and implement a personalized plan to meet individual needs. ${ }^{14,18}$ Solutions might include alternative practice models such as job sharing or restructuring of duties. ${ }^{19}$ Sacks and colleagues highlighted two job-sharing models within academic family medicine where faculty teams distribute conflicting faculty responsibilities. ${ }^{19}$ Providing increased support staff to assist with research, teaching, and patient care, as well as creating technological solutions may reduce workload stress. Time and responsibilities should be proportionally appropriate for positions that require accountability to multiple supervisors, such as faculty/clinical roles or faculty/administrative roles. Foster et all describe how resilience programs have improved mental health nurses coping self-efficacy and capacity to regulate thoughts and emotions in their work environments and organizations. ${ }^{20}$ This approach is supported by a systematic review and meta-analysis by Panagioti and colleagues that describes how organization-directed interventions manage burnout somewhat better than individual faculty-directed interventions. ${ }^{13}$ Some additional areas under institutional control include provision of free or low-cost health and wellness programs, reduction of teaching and/or patient care loads, consolidation of software platforms, and limitations on the use of technology after hour (e.g., checking and responding to email). Academic institutions should examine the mechanisms by which private corporations ensure employee wellness, optimal productivity, and excellent customer service, as they have long recognized that their existence depends on it. Unfortunately, there is little evidence in the literature indicating that academic health care fully recognizes the significance and impact of faculty wellbeing.

\section{CONCLUSION}

Burnout negatively affects pharmacy faculty members as individuals, the longevity of the pharmacy profession, and patient care. Academic institutions are culpable with regard to the expectations, work culture, 


\section{American Journal of Pharmaceutical Education 2020; 84 (7) Article 7925.}

and processes that affect faculty members. Together, the Academy must proactively evaluate, develop, and implement strategies to minimize faculty burnout.

\section{REFERENCES}

1. American Association of Colleges of Pharmacy (AACP). AACP statement on commitment to clinician well-being and resilience. AACP website. https://www.aacp.org/article/commitment-clinicianwell-being-and-resilience. Accessed July 15, 2020.

2. Center for Collegiate Mental Health. Center for Collegiate Mental Health 2018 annual report. https://sites.psu.edu/ccmh/files/2019/01/ 2018-Annual-Report-1.30.19-ziytkb.pdf. Published January 30, 2019. Accessed July 15, 2020.

3. American Association of Colleges of Pharmacy (AACP). Student Affairs: Strategies to Promote a Culture of Well-being among Students and Faculty. AACP website. https://www.aacp.org/event/ fall-institute-2018. Accessed July 15, 2020.

4. Purdue invests in students' mental wellbeing. Purdue University website. https://www.purdue.edu/provost/about/newsletter/nov2018/ across.php\#mental. Published November 1, 2018. Accessed July 15, 2020.

5. Enhancing well-being and resilience among the pharmacist workforce: A national consensus conference. https://www.pharmacist.com/sites/ default/files/audience/APhA_Well_Being_Resilience_Report_\% 200719.pdf Published July 2019. Accessed July 15, 2020.

6. National Academy of Medicine Taking Action Against Clinician Burnout. A Systems Approach to Professional Well-Being. https:// www.nap.edu/catalog/25521/taking-action-against-clinicianburnout-a-systems-approach-to-professional. Published October 23, 2019. Accessed July 15, 2020.

7. El-Ibiary SY, Yam L, Lee KC. Assessment of burnout and associated risk factors among pharmacy practice faculty in the United States. Am J Pharm Educ. 2017;81(4):Article 75.

8. Lee P, Miller MT, Kippenbrock TA, Rosen C, Emory J. College nursing faculty job satisfaction and retention: a national perspective. J Prof Nurs. 2017;33(4):261-266.
9. Reevy GM, Deason G. Predictors of depression, stress, and anxiety among non-tenure track faculty. Front Psychol.

2014;5(1):701.

10. Maslach C, Leiter M. Maslach Burnout Inventory Manual, 3rd ed. Palo Alto, CA: Consulting Psychologists; 1996.

11. 2018-19 profile of pharmacy faculty. American Association of Colleges of Pharmacy website. https://www.aacp.org/system/files? file $=$ 2019-02/PPF1819-final.pdf\&Token $=800$ B056D-C496-43E4873D-66F2F9072D2D. Published February 1, 2019. Accessed July $15,2020$.

12. Golub JS, Johs MM, Weiss PS, Ramesh AK, Ossof RH. Burnout in academic faculty of otolaryngology - head and neck surgery. Laryngoscope. 2008;118(1):1951-1956.

13. Panagioti M, Geraghty K, Johnson J, et al. Association between physician burnout and patient safety, professionalism, and patient satisfaction: a systematic review and meta-analysis. JAMA Intern Med. 2018;178(10):1317-1330.

14. Lin S, Nguyen C, Walters E, Gordon P. Residents' perspectives on careers in academic medicine: obstacles and opportunities. Fam Med. 2018;50(3):204-211.

15. Barton LL, Friedman AD, Locke CJ. Stress in pediatric faculty: results of a national survey. Arch Pediatr Adolesc Med. 1995;149(7):751-757.

16. Scott SA, Maine LL. American Association of Colleges of Pharmacy 2018 annual report. AACP website. https://www.aacp.org/ sites/default/files/2018-07/aacp-annual-report-2018.pdf. Accessed July 15, 2020.

17. Sabagh Z, Hall NC, Saroyan A. Antecedents, correlates and consequences of faculty burnout. Educ Res. 2018;60(2):131-156. 18. Wallace JE, Lemaire JB, Ghali WA. Physician wellness: a missing quality indicator. Lancet. 2009;374(9702):1714-1721. 19. Sacks J, Valin S, Casson RI, Wilson CR. Are 2 heads better than 1? Can Fam Physician. 2015;61(1):11-3.

20. Foster K, Roche M, Delgado C, Cuzzilo C, Giandinoto JA, Furness T. Resilience and mental health nursing: an integrative review of international literature. Int J Ment Health Nurs. 2019;28(1):71-85. 